\title{
Surface modification of cotton fabric to create water repellence property via atom transfer radical polymerization
}

\author{
Shiwei $\mathrm{Li}^{1, \mathrm{a}}$, Zhijuan Liu ${ }^{2, \mathrm{~b}}$, Tieling Xing ${ }^{1, \mathrm{c}}$ and Guoqiang Chen ${ }^{1, \mathrm{~d}, \mathrm{x}}$ \\ ${ }^{1}$ National Engineering Laboratory for Modern Silk, College of Textile and Clothing Engineering, \\ Soochow University, Suzhou 215123, China \\ ${ }^{2}$ Suzhou Zhongke Textile Technology Service Co, Ltd, Suzhou 215228, China \\ alishiwei1988@126.com, bliuzhijuan@fabricschina.com.cn, ${ }^{\mathrm{C}} x$ ingtieling@suda.edu.cn, ${ }^{\mathrm{d}} \mathrm{chenguojian}$ \\ g@suda.edu.cn
}

Keywords: surface modification, dodecafluoroheptyl methacrylate, structure properties, water repellence, atom transfer radical polymerization, cotton fabric.

\begin{abstract}
To enhance the water repellent property of cotton fabric, cotton was grafted using dodecafluoroheptyl methacrylate (DFHMA) monomer via atom transfer radical polymerization (ATRP) method in aqueous media. The structure of grafted cotton fabric was characterized by scanning electron microcopy (SEM) and X-ray photoelectron spectroscopy (XPS). The results showed that DFHMA was successfully grafted onto the surface of cotton fabric. Compared with the control cotton fabric, the surface contact angle test showed that the water repellence of the grafted cotton fabric was better. The surface contact angle of the grafted cotton fabric could reach $150.0^{\circ}$. Furthermore, the washing durability of the grafted fabric was also investigated. The surface contact angle of the grafted cotton fabric could reach $145.3^{\circ}$ after 20 times washing. The whiteness, air permeability and moisture regain of the grafted cotton fabric decreased slightly compared with the control cotton fabric. Cotton fabric with good water repellent property and great washing durability could be obtained, which had little effect on the intrinsic properties of cotton fabric.
\end{abstract}

\section{Introduction}

Cellulose, one of the most abundant natural organic materials, has always been the principal fiber for clothing due to its attractive characteristics $[1,2]$. The unique structure and versatile properties make cellulose very important as a sporting material. Although cotton has large-scale application in many fields, it has bad water repellent property, which limits the utilization of cotton in wide range of areas. Therefore, it is necessary to improve the water repellent property of cotton fabric.

ATRP has been independently developed by Matyjaszewski and Sawamoto in 1995 [3]. It has been successfully used to prepare a wide variety of well-defined polymeric materials including functional polymers, gradient, and segmented copolymers as well as hybrid materials $[4,5]$. The particular advantages of ATRP, well-controlled chain length and low polydispersity, are of great importance for the permanent tailoring of the cellulosic surface.

In this work, cotton was grafted with dodecafluoroheptyl methacrylate (DFHMA) monomer through ATRP in aqueous media [6]. The structure and properties of the grafted cotton fabric were analyzed by different techniques.

\section{Results and Discussion.}

\subsection{Surface morphology.}

The SEM images (Fig. 1) show the surface morphology of control and grafted cotton fabric with DFHMA, respectively. It could be seen that control cotton fibers had a typically smooth surface (Fig. 1a). The surface of DFHMA grafted cotton (Fig. 1b-e) was similar to that of the control cotton. And the surface of cotton fabric was also smooth with graft yield increasing gradually. It showed that grafting had almost no effect on the surface of cotton fabric. The homoploymer on the fabric surface in ATRP grafting system was not so much as the traditional radical grafting system. Because in the 
ATRP grafting system there was no initiator in the grafting solution, theoretically the monomer could only react with the macroinitiator [7].
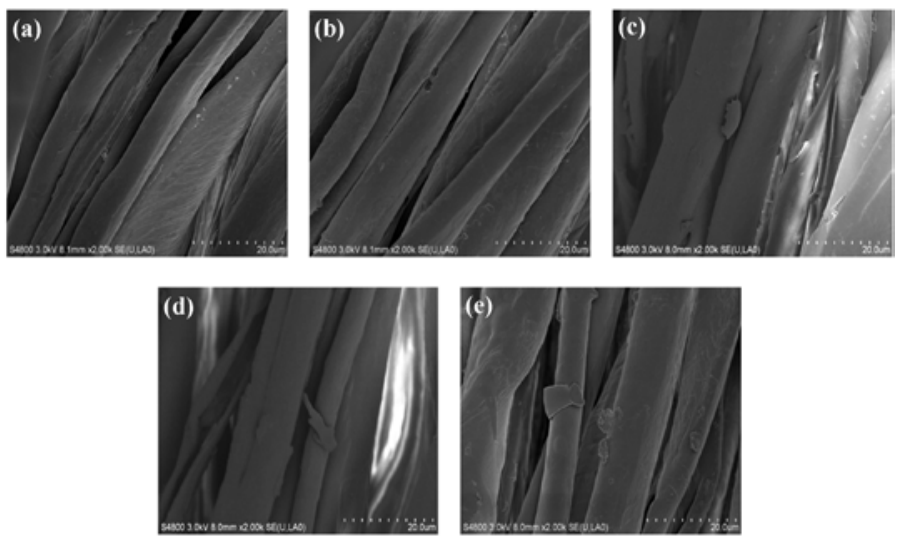

Fig. 1 Scanning electron micrograph of cotton fabric. (a) control cotton sample, DFHMA grafted cotton samples with $10.72 \%$ (b), $19.12 \%$ (c), $25.87 \%$ (d) and $34.42 \%$ (e) of graft yield

\subsection{XPS.}

The respective XPS wide-scan (a) and C1s core-level (b) spectra of the control cotton fabric, and the respective XPS wide-scan (c) and C1s core-level (d) spectra of grafted cotton fabric are shown in Fig. 2.
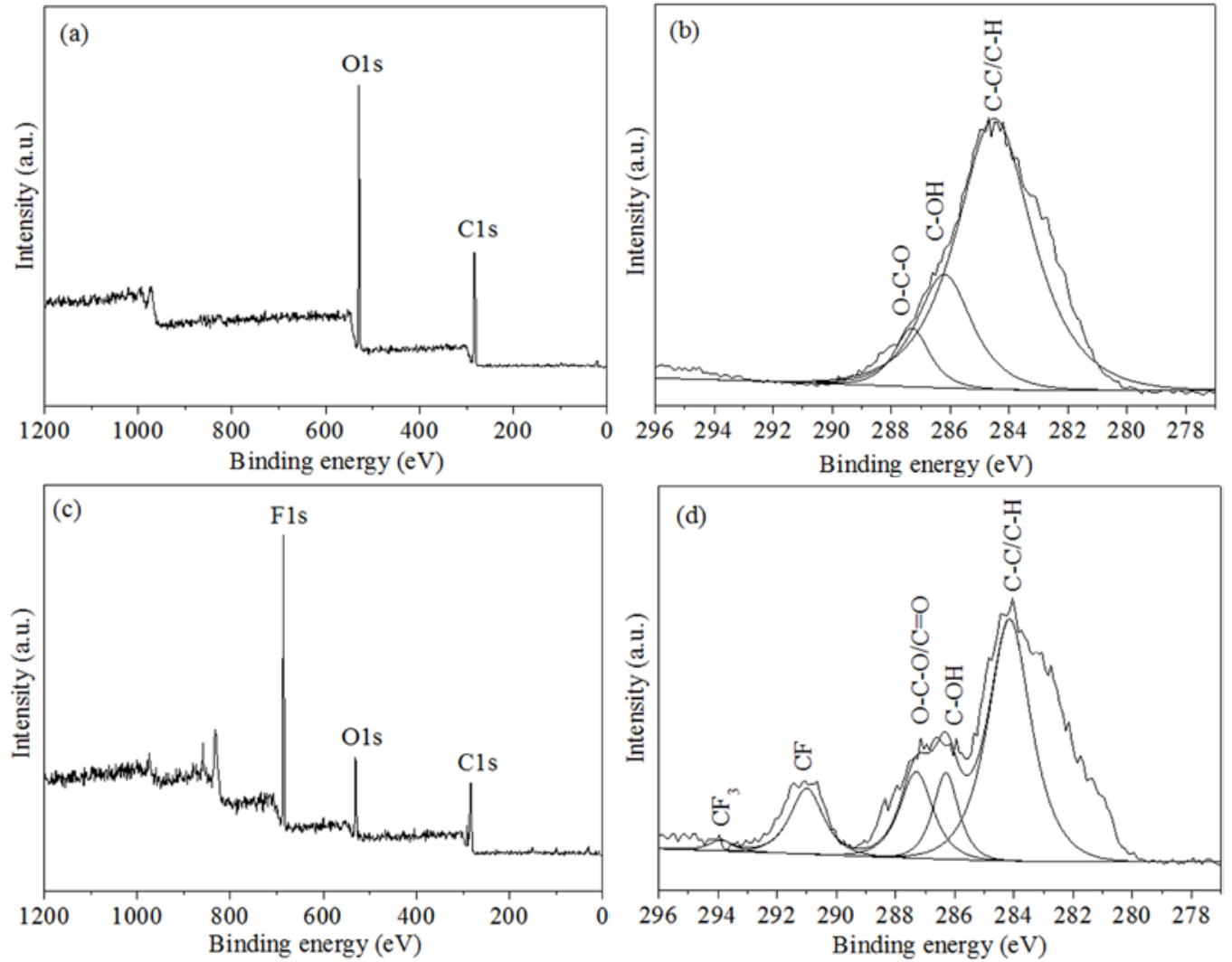

Fig. 2 X-ray photoelectron spectroscopy wide-scan and C1s core-level spectra of control cotton fabric (a and b) and grafted cotton fabric(c and d, $27.19 \%$ of graft yield)

Compared with the typical wide-scan XPS spectrum of control cotton fabric, two major binding energy peaks at $284.9 \mathrm{eV}$ for $\mathrm{C} 1 \mathrm{~s}, 531.7 \mathrm{eV}$ for O1s were almost unchanged. A new peak at $688.2 \mathrm{eV}$ of binding energy occurred for the wide-scan spectrum of grafted cotton fabric, which was attributed to $\mathrm{C}-\mathrm{F}$ bond. In addition, the $\mathrm{C} 1 \mathrm{~s}$ core-level spectrum of the control cotton showed three distinct peaks at $284.4 \mathrm{eV}$ (-C-C-), $286.0 \mathrm{eV}(-\mathrm{C}-\mathrm{OH})$, and $287.3 \mathrm{eV}$ (-O-C-O-). These peaks were attributed 
to the bonds present in the cotton. After grafting treatment, the C1s spectra showed the peaks at 287.3 $\mathrm{eV}(-\mathrm{C}=\mathrm{O}), 290.9 \mathrm{eV}(-\mathrm{CF})$, and $293.8 \mathrm{eV}\left(-\mathrm{CF}_{3}\right)$ [8, 9]. The XPS indicated that fluorine containing side chain covered or distributed onto cotton fabric surface.

\subsection{Surface contact angle.}

The surface contact angle of cotton fabrics are listed in Table 1. As graft yield increasing gradually, the water contact angle of cotton fabric increased. When graft yield was $34.42 \%$, the surface contract angle of DFHMA grafted cotton fabric was $150.0^{\circ}$, which indicated that the grafted cotton fabric obtained good water repellence property. And the surface contact angle of DFHMA grafted cotton fabric did not increase when graft yield achieved 38.87\%. The grafting occurred mainly in the amorphous region of cotton, and DFHMA might block certain hydrophilic groups of cotton macromolecules, which decreased the hygroscopic properties of cotton fabrics. In addition, the fluorine containing long carbon chain was surrounded by the fluorine atoms, and the fluorine-containing segment spread onto the fabric surface. It formed a special brush-like structure which could reduce the surface tension of the fabric and formed more remarkable space shielding effect. When the graft yield increased to a certain degree, it had no promoting effect to the surface contact angle because the density of cotton fabric surface fluoride groups reached saturation. The results of washing fastness testing after $0,5,10,15$ and 20 times of washing show that the surface contact angle of the grafted cotton fabrics have better water repellence compared with the control fabric. With the washing times increasing, the surface contact angle just slightly decreased, which can be explained by the fact that the washing would not affect the covalent bond between cotton and DFHMA. Consequently, the grafted cotton fabrics had a great washing durability.

Table 1 Water contact angles of cotton fabrics with various washing times

\begin{tabular}{ccccccc}
\hline \multirow{2}{*}{ Samples } & \multirow{2}{*}{$\begin{array}{c}\text { Graft } \\
\text { yield (\%) }\end{array}$} & $\begin{array}{c}\text { Surface contact angle }\left(^{\circ}\right) \\
\text { after 0 times } \\
\text { washing }\end{array}$ & $\begin{array}{c}\text { after 5 times } \\
\text { washing }\end{array}$ & $\begin{array}{c}\text { after 10 times } \\
\text { washing }\end{array}$ & $\begin{array}{c}\text { after 15 times } \\
\text { washing }\end{array}$ & $\begin{array}{c}\text { after 20 times } \\
\text { washing }\end{array}$ \\
\hline Control & 0 & 0 & 0 & 0 & 0 & 0 \\
\hline \multirow{2}{*}{ DFHMA } & 12.92 & 143.5 & 140.5 & 139.6 & 139.1 & 138.4 \\
graft & 27.50 & 149.0 & 148.3 & 147.8 & 145.5 & 144.7 \\
& 34.42 & 150.0 & 148.6 & 147.4 & 146.1 & 145.3 \\
& 38.87 & 140.1 & 138.3 & 137.8 & 136.5 & 134.2 \\
\hline
\end{tabular}

\subsection{Physical Properties.}

It can be seen from Table 2 that the whiteness, air permeability and moisture regain of grafted cotton fabric slightly decreased compared with the control sample.

Table 2 Whiteness, permeability and moisture regain of cotton fabric

\begin{tabular}{ccccc}
\hline Samples & Graft yield (\%) & Whiteness (\%) & Air permeability $(\mathrm{mm} / \mathrm{s})$ & Moisture regain (\%) \\
\hline Control & 0 & 81.8 & 119.0 & 9.4 \\
\hline \multirow{3}{*}{ DFHMA graft } & 12.92 & 69.9 & 89.2 & 5.3 \\
& 27.50 & 67.2 & 80.9 & 5.0 \\
& 34.42 & 64.5 & 79.2 & 3.8 \\
\hline
\end{tabular}

With the increase of graft yield, the air permeability of the grafted cotton fabric decreased. This was due to the pore size between the interstices of cotton fibers became smaller, which derived from the grafting of DFHMA monomer onto the cotton fabric. A decrease of whiteness of grafted cotton fabric was noticed owing to the influence of TEA and metal catalyst after the grafting treatment. The decline of moisture regain was attributed to the decrease of grafted cotton surface hydrophilic groups and the space shielding effect of fluoride groups. However, under the circumstances of less affecting 
the intrinsic properties of cotton fabric, cotton with good water repellence property could be obtained by properly controlling the graft yield.

\section{Conclusions.}

In this study, DFHMA was covalently bonded onto the surface of cotton fabric via ATRP method. The SEM and XPS analysis results confirmed that DFHMA was successfully grafted on the surface of the cotton fabric. The surface contact angle of the grafted cotton fabric could reach $150.0^{\circ}$, and the contact angle of grafted cotton fabric increased with the graft yield increasing. The grafted cotton fabric had a good washing durability. Cotton fabric with good water repellent property was successfully obtained, which had little effect on the fabrics wear ability.

\section{Acknowledgements.}

This work was supported by National Natural Science Foundation of China (nos. 51203107 and 51273134) and Natural Science Foundation of Jiangsu Province (nos. BK20130313 and BK20140400) sponsored by Qing Lan Project and the Priority Academic Program Development of Jiangsu Higher Education Institutions. In addition, the Jiangsu Province Project of Postgraduate Innovation Engineering (no CXZZ13_0818) is really appreciated as the article is a part of it.

\section{References}

[1]. Bianchi E, Marsano E, Ricco L, et al. Free radical grafting onto cellulose in homogeneous conditions.1. Modified cellulose-acrylonitrile system. Carbohydr Polym. Vol. 36 (1998) No. 4, p. 313-318.

[2]. Bianchi E, Bonazza A, Marsano E, et al. Free radical grafting onto cellulose in homogeneous conditions.2. Modified cellulose-methylmethacrylate system. Carbohydr Polym. Vol. 41 (2000) No. 1, p. 47-53.

[3]. Kato M, Kamigaito M, Sawamoto M, et al. Polymerization of methyl methacrylate with the carbon tetrachloide/dichlorotris (triphenylphosphine) ruthenium ( II )/methylaluminum bis (2, 6-di-tert- butylphenoxide) initiating system: possibility of living radical polymerization. Macromolecules. Vol. 28 (1995) No. 5, p. 1721-1723.

[4]. Tsarevsky NV, Matyjaszewski K. Combining atom transfer radical polymerization and disulfide/thiol redox chemistry: a route to well-defined (bio) degradable polymeric materials. Macromolecules. Vol. 38 (2005) No. 8, p. 3087-3092.

[5]. Wang Y, Zhang YZ, Parker B, et al. ATRP of MMA with ppm levels of iron catalyst. Macromolecules. Vol. 44 (2011) No. 11, p. 4022-4025.

[6]. Li SW, Xing TL, Li ZX, et al. Structure and properties of cotton grafted using trifluoroethyl methacrylate via ATRP method. Advanced Materials Research. Vol. 796 (2013). P. 364-369.

[7]. Xing TL, Liu J, Li SW. Surface-initiated atom transfer radical polymerization on cotton fabric in water aqueous. Text Res J. Vol. 83 (2013) No. 4, p. 363-370.

[8]. Li SW, Xing TL, Li ZX, et al. Structure and properties of silk grafted with acrylate fluoride monomers by ATRP. Appl Surf Sci. Vol. 268 (2013). p. 92-97.

[9]. Lee J, Kang MH, Lee KB, et al. Characterization of natural dyes and traditional korean silk fabric by surface analytical techniques. Materials. Vol. 6 (2013) No. 5, p. 2007-2025. 